Terr. Atmos. Ocean. Sci., Vol. 17, No. 4, I-VI, December 2006

\title{
Preface to the Special Issue on Gas Hydrate Research around the South China Sea and Taiwan
}

\author{
Tsanyao Frank Yang, Char-Shine Liu, Ju-Chin Chen and Chi-Yue Huang
}

Gas hydrates are naturally occurring crystalline substances, in which a solid water lattice holds gas molecules in a cage-like structure. They have attracted much attention as an alternative energy resource potential, and may impact the global environment through generating slope instability. Consequently, much research utilizing different approaches has been carried out recently for better understanding the origin and characteristics of gas hydrates.

Bottom simulating reflector (BSR) is a strong indicator of gas hydrate presence and extensive BSRs have been clearly observed in many parts of the continental margins around the South China Sea, especially in SW offshore Taiwan. Since 2004, the Central Geological Survey (CGS) of the Ministry of Economic Affairs (MOEA) has launched a 4-year gas hydrate investigation program that includes geological investigation, geochemical exploration, geophysical survey, and data bank establishment. Some important and exciting results have been found during the early stages of this investigation. In order to share the findings and to better develop the gas hydrate investigation program in Taiwan, an international workshop and a cross-Strait conference on gas hydrates were held in Taipei and Tainan in November 2004 and January 2005, respectively. After these successful and fruitful conferences, we invited colleagues to submit their updated results to this journal for a special issue reporting on the most recent progress in gas hydrate studies for the region.

A total of twenty-two representative contributions have been included in this special issue after passing through a regular peer review process. They are divided into four groups: (1) the general geology and characteristics of gas hydrates around the South China Sea region; (2) the results of geophysical investigations in the South China Sea and East China Sea; (3) the geochemical investigations in this region; and (4) some important findings regarding physical properties of potential gas hydrate bearing samples.

In the first group of six papers, Liu et al. (2006) describe the distribution and characters of gas hydrate offshore of SW Taiwan based on seismic data, and find that intensive BSRs can be recognized in both active and passive margins. They also briefly report on current progress in the integrated project for gas hydrate exploration supported by the CGS. From the newly collected geophysical and geologic data, Yan et al. (2006) demonstrate the occurrences of gas hydrates in the continental margins of the northeastern South China Sea near Dongsha Island. Yu and Huang (2006) discuss sedimentary processes through seismic facies analyses and recognize three intraslope basins in the area off SW Taiwan, which they consider to be the result of interactions between regional contraction tectonics, local mud diapirism and foreland sedimentation. Huang et al. (2006) report the occurrence of pogonophoran tube worms, elongated pyrites and authigenic carbonate nodules in the Kaoping Slope, and evaluate the occurrences of potential cold seeps in the syn-collision accretionary prism off SW Taiwan. They suggest that there are active cold seeps with methane expulsions in the area. Numerous mud volcanoes and gassy sediments have been identified in both the passive and active margins 
offshore of SW Taiwan along chirp sonar and seismic reflection profile data by Chiu et al. (2006). They suggest that these gassy sediments and mud volcanoes could be formed due to fluids escaping from dewatering sedimentary layers that form mud diapirs, or along faults and fractures where free gases or gases from dissociated gas hydrates migrated to the seafloor. Based on the thermodynamic characteristics of gas hydrates, Chen et al. (2006) group the gas hydrates in a marine environment into two categories, the diffusion gas hydrate and the vent gas hydrate. They consider these two types of gas hydrate exhibit distinct characters in occurrence, gas source, manner of gas migration, and system thermodynamics. Furthermore, they conclude that both types of gas hydrates possibly occur in the South China Sea.

In the second group, eight papers present the results of systematic geophysical survey in the South China Sea and East China Sea. Cheng et al. (2006) report the first time usage of ocean bottom seismometers (OBSs) for gas hydrate study in this region, and established the velocity structure of the sedimentary layers by modeling the vertical component data of OBSs. Schnürle et al. (2006) ultilized 3 independent velocity analysis methods on 6 OBS records of a 2.5-D seismic experiment to determine the acoustic and shear-wave velocities of the sediments. Velocity profiles with rapid lateral and vertical variations of the velocities in the accretionary complex offshore of SW Taiwan were obtained and gas hydrate content in the sediments through rock physics model are discussed. Deng et al. (2006) perform seismic attributes analyses along a seismic profile in the accretionary prism offshore of SW Taiwan, and suggest that a gas hydrate layer exists together with a free gas layer below it along a strong BSR beneath gas hydrate bearing sediments. X. Wang et al. (2006) use constrained sparse spike inversion method to provide information on rock properties and suggest that gas hydrate saturation in the Taixinan Basin is about $10-20 \%$ of the pore space, with the highest value of $50 \%$, and free gas saturation below BSR is about $2-3 \%$ of the pore space, that can rise to $8-10 \%$ at a topographic high. Based on the relationship between the gas hydrate stability zone (GHSZ) thickness and water depth, S. Wang et al. (2006) estimate the thicknesses of the GHSZ in the South China Sea for three kinds of gas hydrates, and give rough estimations on the total amount of gas hydrate in the South China Sea. Similarly, Chi et al. (2006) estimate the total volume of gas hydrate off southern Taiwan from the thickness of the GHSZ bounded between the seafloor and the mapped BSR. Shyu et al. (2006) analyzed 23 heat flow measurements offshore of SW Taiwan where obvious BSRs are observed. They report that the average depth of the base of the GHSZ is 304 mbsf based on their heat flow data versus averaged BSR depths of 358 mbsf, and the heat flow increases from the coastal waters southward to the front of the accretionary wedge. Xu et al. (2006) discuss the movement and accumulation of free gas relating to the mud diapirs in the Okinawa Trough using the fluid potential analysis approach, and conclude that the high fluid potential anomaly on the low fluid potential background may be caused by the presence of the free gas below the gas hydrate bearing strata.

In the third group of six papers, the results of systematic geochemical survey on fluid and gas samples in the South China Sea are presented. Lin et al. (2006) show a very fast sulfate reduction rate in pore waters from cored sediments in the northern part of continental margin of the South China Sea. Very high methane concentrations were also found in both bottom water (Chuang et al. 2006) and pore space of cored sediments (Chuang et al. 2006; Oung et al. 2006), and also water column samples (Chen and Tseng 2006; Yang et al. 2006), especially in 
the active margin of the study area. Overall, all the geochemical data, including high methane and dissolved sulfide concentration, high sulfate reduction rate, shallow depth of sulfate-methane-interface, and the carbon isotopic composition of the authigenic carbonates etc., support the conclusion that there is/was a very high methane flux and actively venting in the gas hydrate potential area offshore of SW Taiwan. Chao and You (2006) performed B and Cl chemical and isotopic analysis for the pore waters separated from piston cores off SW Taiwan and found that strong influence from organic matter degradation during diagenesis at shallow depths and the possible addition of deep fluids advecting through mud diapir channels at greater depths caused a minor degree of hydrate dissolution/formation to occur at shallow depths.

In the last group of two papers, Jiang et al. (2006) present detailed mineralogy and physical properties of cored sediments from the gas hydrate potential area of offshore SW Taiwan. They found prominent overgrowth microstructures on authigenic pyrite framboids at shallow depths, which are consistent with the phenomenon of sulfate reduction and pyrite precipitation relating to migration and oxidation of methane, which was possibly released from gas hydrate zones at later stages of early diagenesis. Horng and Chen (2006), on the other hand, present the results of down core variations in magnetic susceptibility and magnetic mineral composition of piston cores retrieved from the active continental margin offshore of SW Taiwan. The complicated occurrence of magnetic minerals reveals that their host sediments at different levels have suffered various degrees of diagenetic processes ranging from oxic to anoxic conditions.

Over all, this special issue is the first collection of gas hydrate research papers in SE Asia that includes updated results from various investigations in the South China Sea and Taiwan. It not only provides important basic data in the area, but readers will also learn the most recent techniques and approaches being applied to these works. We hope this special issue can become an important reference not only for local scientists but also for those who are working and/or concerned with gas hydrate research in other parts of the world.

We are grateful to all the authors and to the reviewers (listed below), who made this special issue possible: N. Bangs (Univ. Texas), S. Boggs (Univ. Oregon), D. Brown (Instituto de Ciencias de la Tierra "Jaume Almera", Spain), C. Chen (National Central Univ.), G. Etiope (INGV, Italy), S. C. Fuh (Chinese Petroleum Company), M. Hato (Kyoto Univ.), I. C. E. Huang (ChungChou Institute Technology), W. L. Huang (National Taiwan Univ.), D. G. Huh (KIGAM, Korea), R. D. Hyndman (Geological Survey of Canada), W. L. Jeng (National Taiwan Univ.), U. Knittel (TU Bergakademie Freiberg, Germany), T. Y. Lee (National Taiwan Normal Univ.), Y. J. Lee (KIGAM, Korea), A. T. Lin (National Central Univ.), H. L. Lin (National Sun Yat-Sen Univ.), S. M. Liu (National Taiwan Ocean Univ.), H. Lu (National Research Council, Canada), S. Lu (ChevronTexaco), R. Matumoto (Univ. Tokyo), A. Milkov (British Petroleum, Houston), Y. Sano (Univ. Tokyo), Y. N. Shieh (Purdue Univ.), R. C. Shih (National Chung Cheng Univ.), G. Snyder (Rice Univ.), S. R. Song (National Taiwan Univ.), C. H. Sun (Chinese Petroleum Corporation), L. S. Teng (National Taiwan Univ.), M. Torii (Okayama Univ. of Science), C. H. Wang (Academia Sinica), T. K. Wang (National Taiwan Ocean Univ.), A. Waseda (Japan Petroleum Exploration Co. Ltd.), K. Y. Wei (National Taiwan Univ.), P. Yin (State Oceanic Administration, China).

Finally, we dedicate this special issue to the Central Geological Survey of MOEA, Re- 
public of China for their continuous support and promotion of gas hydrate studies in Taiwan that made the present progress possible. The CGS financially supported the publication of this special issue. Special thanks are due to the associate editor, Dr. Bor-Shouh Huang, who carefully handled this special issue.

\section{REFERENCES}

Chao, H. C., and C. F. You, 2006: Distribution of B, Cl and their isotopes in pore waters separated from gas hydrate potential areas, offshore southwestern Taiwan. Terr. Atmos. Ocean. Sci., 17, 961-979.

Chen, C. T. A., and H. C. Tseng, 2006: Abnormally high $\mathrm{CH}_{4}$ concentrations in seawater at mid-depths on the continental slopes of the northern South China Sea. Terr. Atmos. Ocean. Sci., 17, 951-959.

Chen, D. F., Z. Su, and L. M. Cathles, 2006: Types of gas hydrates in marine environments and their thermodynamic characteristics. Terr. Atmos. Ocean. Sci., 17, 723-737.

Cheng, W. B., C. S. Lee, C. S. Liu, P. Schnürle, S. S. Lin, and H. R. Tsai, 2006: Velocity structure in marine sediments with gas hydrate reflectors in offshore SW Taiwan, from OBS data tomography. Terr. Atmos. Ocean. Sci., 17, 739-756.

Chi, W. C., D. L. Reed, and C. C. Tsai, 2006: Gas hydrate stability zone in offshore southern Taiwan. Terr. Atmos. Ocean. Sci., 17, 829-843.

Chiu, J. K., W. H. Tseng, and C. S. Liu, 2006: Distribution of gassy sediments and mud volcanoes offshore southwestern Taiwan. Terr. Atmos. Ocean. Sci., 17, 703-722.

Chuang, P. C., T. F. Yang, S. Lin, H. F. Lee, T. F. Lan, W. L. Hong, C. S. Liu, J. C. Chen, and Y. Wang, 2006: Extremely high methane concentration in bottom water and cored sediments from offshore southwestern Taiwan. Terr. Atmos. Ocean. Sci., 17, 903-920.

Deng, H., P. Yan, H. Liu, and W. Luo, 2006: Seismic data processing and the characterization of a gas hydrate bearing zone offshore of southwestern Taiwan. Terr. Atmos. Ocean. Sci., 17, 781-797.

Horng, C. S., and K. H. Chen, 2006: Complicated magnetic mineral assemblages in marine sediments offshore of southwestern Taiwan: possible influence of methane flux on the early diagenetic process. Terr. Atmos. Ocean. Sci., 17, 1009-1026.

Huang, C. Y., C. W. Chien, M. Zhao, H. C. Li, and Y. Iizuka, 2006: Geological study of active cold seeps in the syn-collision accretionary prism Kaoping slope off SW Taiwan. Terr. Atmos. Ocean. Sci., 17, 679-702.

Jiang, W. T., J. C. Chen, B. J. Huang, C. J. Chen, Y. T. Lee, P. R. Huang, C. C. Lung, and S. W. Huang, 2006: Mineralogy and physical properties of cored sediments from the gas hydrate potential area of offshore southwestern Taiwan. Terr. Atmos. Ocean. Sci., 17, 981-1007.

Lin, S., W. C. Hsieh, Y. C. Lim, T. F. Yang, C. S. Liu, and Y. Wang, 2006: Methane migration and its influence on sulfate reduction in the Good Weather Ridge region, South China Sea continental margin sediments. Terr. Atmos. Ocean. Sci., 17, 883-902. 
Liu, C. S., P. Schnürle, Y. Wang, S. H. Chung, S. C. Chen, and T. H. Hsiuan, 2006: Distribution and characters of gas hydrate offshore of southwestern Taiwan. Terr. Atmos. Ocean. Sci., 17, 615-644.

Oung, J. N., C. Y. Lee, C. S. Lee, and C. L. Kuo, 2006: Geochemical study on hydrocarbon gases in seafloor sediments, southwestern offshore Taiwan - implications in the potential occurrence of gas hydrates. Terr. Atmos. Ocean. Sci., 17, 921-931.

Schnürle, P., C. S. Liu, and C. S. Lee, 2006: Acoustic and shear-wave velocities in hydratebearing sediments offshore southwestern Taiwan: tomography, converted waves analysis and reverse-time migration of OBS records. Terr. Atmos. Ocean. Sci., 17, 757-779.

Shyu, C. T., Y. J. Chen, S. T. Chiang, and C. S. Liu, 2006: Heat flow measurements over bottom simulating reflectors, offshore southwestern Taiwan. Terr. Atmos. Ocean. Sci., 17, 845-869.

Wang, S., W. Yen, and H. Song, 2006: Mapping the thickness of the gas hydrate stability zone in the South China Sea. Terr. Atmos. Ocean. Sci., 17, 815-828.

Wang, X., S. Wu, N. Xu, and G. Zhang, 2006: Estimation of gas hydrate saturation using constrained sparse spike inversion: case study from the northern South China Sea. Terr. Atmos. Ocean. Sci., 17, 799-813.

Xu, N., S. Wu, X. Wang, and D. Dong, 2006: The characteristics of fluid potential in mud diapirs associated with gas hydrates in the Okinawa Trough. Terr. Atmos. Ocean. Sci., 17, 871-881.

Yan, P., H. Deng, and H. Liu, 2006: The geological structure and prospect of gas hydrate over the Dongsha Slope, South China Sea. Terr. Atmos. Ocean. Sci., 17, 645-658.

Yang, T. F., P. C. Chuang, S. Lin, J. C. Chen, Y. Wang, and S. H. Chung, 2006: Methane venting in gas hydrate potential area offshore of SW Taiwan: evidence of gas analysis of water column samples. Terr. Atmos. Ocean. Sci., 17, 933-950.

Yu, H. S., and Z. Y. Huang, 2006: Intraslope basin, seismic facies and sedimentary processes in the Kaoping slope, offshore southwestern Taiwan. Terr. Atmos. Ocean. Sci., 17, 659-677.

Yang, T. F., C. S. Liu, J. C. Chen, and C. Y. Huang, 2006: Preface to the special issue on Gas Hydrate Research around the South China Sea and Taiwan. Terr. Atmos. Ocean. Sci., 17, I-VI. 


\section{Responsible Editor:}

Bor-Shouh Huang

Institute of Earth Sciences, Academia Sinica

E-mail:hwbs@earth.sinica.edu.tw

\section{Guest Editors:}

Ju-Chin Chen

Institute of Oceanography, National Taiwan University

jcchen@oc.ntu.edu.tw

Char-Shine Liu

Institute of Oceanography, National Taiwan University

E-mail: csliu@ntu.edu.tw

Chi-Yue Huang

Department of Earth Sciences, National Cheng Kung University

E-mail: huangcy@mail.ncku.edu.tw

\section{Executive Guest Editor:}

Tsanyao Frank Yang

Department of Geosciences, National Taiwan University

E-mail: tyyang@ntu.edu.tw 